\title{
Progress of optimal operation for large pumping station system
}

\author{
X.L. FENG \& B.Y. QIU \\ Yangzhou University, Yangzhou, China
}

\begin{abstract}
Keyword: Large pumping station; Operation scheme; Optimal model; Optimal method Abstract: The research ranges of optimal operation for large pumping stations were analyzed. Energy losses of power transmission and transformation, pumping stations and water transmission should be considered when optimal models are constituted. Under the circumstances of pumping certain discharge or volume, aiming at the lowest operation cost, optimal models were established considering head variation and time-varying electrical price for single or parallel pumping stations and step pumping station system. Research progress of optimization methods to the models was introduced, and the research trends were pointed out.
\end{abstract}

\section{INTRODUCTION}

Large pumping station plays a key role in aspects of irrigation, drainage, water diversion, city water supply and drainage, and ecological environment improvement. Meantime, when the pumping station is running, amounts of energy and high operation cost are consumed.

According to the investigation, the optimal operation is not really realized for most of the pumping stations in our country, and the energy waste is serious. A lot of researches both at home and abroad have been done for optimal operation of pumping stations, but the factors are not considered comprehensively. Also, the calculating speed and accuracy could be improved for the optimization method, as well as the optimizing effect.

\section{OPTIMIZING RANGE AND GOALS}

The research range is enlarged gradually for optimal operation of large pumping station. The study is developed from the economical operation of a pump or a pump assembly to that of a single pumping station, parallel pumping stations, and multi-stage pumping stations. The optimization goals mainly focused on the efficiency and the cost. At first, only pump efficiency is required high, but the pump assembly efficiency is not high. Then, the highest efficiency of the pump assembly and the pumping station is gradually regarded as the optimization goal.

Qiu B Y, et al. (2005) studied the efficiency features of the pump assembly in the large pumping station, and proposed the adjustment methods of operation modes. Tang Y, et al. (2010) studied the optimal operation of water supply system by regulating the variable speed of a pump to save energy. Taking the minimum operating electricity as the goal, Chen S L, et al. (2003) determined the total water distribution on each period and unit, under the condition of a given pumping amount. Coelho B \& Andrade-Campos A(2014) studied the measures and methods to improve the efficiency of water supply system, from the demand forecast, network design, the pump real-time running. Vilanova M R N \& Balestieri J P(2014) put forward advanced methods to save energy and improve the hydraulic efficiency for a water supply system.

In fact, in order to complete the task of water diversion from water source to the destination for large pumping station, power transmission and transformation, pumping stations and water transfer facility are all indispensable, and the three are respectively in charge of electricity, energy transformation and water transport. Energy loss is inevitable during their operation.

For the total input power of pumping station system, parts power is changed into useful effective power, and the other is changed into losses of power transmission, transformer, frequency conversion device, motor power, driving mechanism, the main water pump, inlet and outlet passage, auxiliary equipments, and water channel, etc.

We have carried on the preliminary calculation and analysis of energy consumption on several typical pumping station system in jiangsu province of China, the results show that the energy loss of power transmission and transformation and auxiliary equipments accounts for about $2 \%-6 \%$ of the whole pump station system input power, the water pump system (including transmission facilities, 
pump assembly, driving device, motor and auxiliary equipment) highest efficiency is deviating in the highest pump assembly efficiency, so there are energy saving potential and space in the system.

In short, large pump station operation optimization should take the whole system as the research object, comprehensively considering three aspects such as power transmission and transformation, pumping stations and water transfer facilities.

\section{OPTIMIZING MODELS}

\section{Single-stage pumping station}

For single pumping station, the researches mainly determine the type and the number of running pumps, and the operation duty, aiming at the total water flow requirements (Anagnostopoulos J S, et al. 2007). If the user requirement is the amount of pumping within a certain period of time, you have to optimize the water flow at different time periods (Moreno M A, et al. 2007). For parallel pumping station group, it is necessary to consider which pumping station to operation (Feng X L, et al. 2008). If the time varying electricity price is carried out, the problem will be more complex (Feng X L, et al. 2009).

(1) Under the condition of certain pumping capacity and assembly head, if taking the minimum electricity cost of main unit operation as the optimization goal, the objective function could be expressed as:

$$
F=\min \sum_{i=1}^{I} \frac{\rho g Q_{i} H_{\mathrm{z}} \cdot n_{i}}{1000 \eta_{\mathrm{zi}} \cdot \eta_{\mathrm{dr} i} \cdot \eta_{\mathrm{moti}}} \cdot t \cdot p
$$

At the same time, the function should meet the single flow constraints, the number of running pump constraints, and total pumping flow constraints, namely

$$
\begin{gathered}
Q_{i, \min } \leq Q_{i} \leq Q_{i, \max } \\
n_{i} \leq M_{i} \\
\sum_{i=1}^{I} Q_{i} \cdot n_{i}=Q_{\mathrm{z}}
\end{gathered}
$$

Where $F$ is electricity cost; $i$ is the $i^{\text {th }}$ pump type; $I$ is the total number of pump types; $\rho$ is water density; $\mathrm{g}$ is acceleration of gravity; $Q$ is flow rate; $H_{\mathrm{z}}$ is pump assembly head; $\eta_{\mathrm{z}}$ is pump assembly efficiency; $n$ is the number of running pumps; $\eta_{\text {mot }}$ is motor efficiency; $\eta_{\mathrm{dr}}$ is driving efficiency; $t$ is running time; $p$ is electricity price; $M$ is the number of installing pumps; $Q_{z}$ is total pumping discharge.

(2) Under the condition of certain pumping volume of water, if taking the minimum electricity cost of main unit operation as the optimization goal, and considering head varying and time varying electricity price, the objective function could be expressed as:

$$
F=\min \sum_{j=1}^{J} \sum_{i=1}^{I} \frac{\rho g Q_{j i} H_{z j} \cdot n_{j i}}{1000 \eta_{z j i} \cdot \eta_{\mathrm{drji}} \cdot \eta_{\operatorname{mot} j i}} \cdot t_{j} \cdot p_{j}
$$

Besides the constraints (2) and (3), the constraints of pump assembly head and total pumping discharge is required, namely

$$
H_{z j, \min } \leq H_{z j} \leq H_{z j, \max } \quad \text { (6) } \sum_{j=1}^{J} \sum_{i=1}^{I} Q_{j i} \cdot n_{j i} \cdot \Delta T_{j}=V_{\mathrm{z}}
$$

Where $j$ is serial number of time periods; $J$ is the number of time periods; $V_{z}$ is total pumping volume. Other symbolic has the meaning with the above.

(3) Under the condition of certain pumping volume of water, if taking the minimum electricity cost of the whole pumping station system as the optimization goal, and considering time varying electricity price, the objective function could be expressed as:

$$
\begin{aligned}
F=\min [ & \sum_{j=1}^{J} \sum_{i=1}^{I}\left(\frac{\rho g Q_{j i} H_{\mathrm{z} j} \cdot \eta_{j i}}{1000 \cdot \eta_{\mathrm{zji}} \cdot \eta_{\mathrm{d} j \mathrm{i}} \cdot \eta_{\mathrm{mot} j i}}+P_{\mathrm{zn} j i}+\Delta P_{\mathrm{telj} j}\right)+ \\
& \left.\sum_{k=1}^{K} \Delta P_{\mathrm{b} k}+\Delta P_{\mathrm{tehj}}\right] \cdot t_{j} \cdot p_{j}
\end{aligned}
$$


The constraints are the expression (2), (3), (6) and (7). Where $P_{\mathrm{zn}}$ is station energy cost; $\Delta P_{\text {tel }}$ is low voltage side transmission loss of the main transformer; $\Delta P_{\mathrm{b}}$ is main transformer loss; $\Delta P_{\text {teh }}$ is high voltage side transmission loss of the main transformer; $k$ is the serial number of main transformers.

\section{Multi-stage pumping station}

For multi-stage pumping stations, it is necessary to consider the optimization of pump station head and flow rate between higher and lower stage, and the flow distribution of different routes. Also, other factors could not be neglected, such as the length of river, hydraulic loss, water loss and the characteristics of flow rate and efficiency of the pump units $(\mathrm{Wu} \mathrm{H}$, et al. 2014, Skworcow P, et al. 2014).

Under the condition of certain water level of source and destination and pumping volume of water, if taking the minimum electricity cost of the whole multi-stage pumping station system as the optimization goal, the objective function could be expressed as:

$$
\begin{gathered}
F=\min \sum_{i=1}^{I} f_{i} \\
f_{i}=\sum_{j=1}^{J} \sum_{k=1}^{K}\left[\left(\frac{\rho g Q_{i j k} H_{\mathrm{zi}} \cdot n_{i j k}}{1000 \cdot \eta_{\mathrm{z} i j k} \cdot \eta_{\mathrm{dr} i j k} \cdot \eta_{\mathrm{mot} i j k}}\right)+\right. \\
\left.P_{\mathrm{zn} i j}+\Delta P_{\mathrm{tel} i j}+\Delta P_{\mathrm{b} i j}+\Delta P_{\mathrm{teh} i j}\right] \cdot t \cdot p
\end{gathered}
$$

The constraints are expression (2), (3), (6) and (11). And the Eq. (11) is as follows:

$$
\sum_{i=1}^{I} \sum_{j=1}^{J} \sum_{k=1}^{K} Q_{i j k} \cdot n_{i j k}-\sum_{l=1}^{L}\left(q_{\mathrm{zl}}+q_{\mathrm{sl}}\right)=Q_{\mathrm{e}}
$$

Where $I(i=1,2, \ldots, I)$ is the $i^{\text {th }}$ stage pumping station; $j(j=1,2, \ldots, J)$ is the $j^{\text {th }}$ pumping station; $k$ $(k=1,2, \ldots, K)$ is the $k^{\text {th }}$ pump type; $l(l=1,2, \ldots, L)$ is the $l^{\text {th }}$ section channel; $q_{\mathrm{z}}$ is water evaporation loss; $q_{\mathrm{s}}$ is water leakage loss.

\section{OPTIMIZING METHODS}

From the point of the existing research, due to the complexity and many factors of the pumping station system, in order to determine optimal operation schemes for pumping stations, pump station optimal operation mathematical models are established based on the operation requirements and the optimization goals. Most models are nonlinear with equality constraints and inequality constraints optimization model, so it is more complicated and difficult to solve. Applied to the optimization of pump stations, optimal methods mainly include static programming method, dynamic programming and intelligent optimization algorithms, etc.

\section{Static programming method}

Static programming is relative to dynamic programming, and concludes integer programming, linear and nonlinear programming.

Puleo V, et al. (2014) regarded the discharge as decision variables, and determined the 24 hours pump running schemes by linear programming method, meanwhile, the results were verified by mixed discrete dynamically dimensioned search.

Ghaddar B, et al. (2015) put forward a mixed integer nonlinear programming method to research the operation control of a pump system, and the model was solved by the Lagrangian decomposition method with remarkable energy-saving.

Aiming at the minimum cost of pipeline and pumping operation, Theocharisa M E, et al. (2010) studied the operation optimization of irrigation systems by the simplified nonlinear programming method, and applied traditional Labye method and linear programming method to verify the validity of the new method.

Ommen T, et al. (2014) studied three methods such as linear programming, mixed integer programming and nonlinear programming in energy system dispatch modeling, from the calculation accuracy and the running time.

Integer programming is suitable for solving the optimization model of variable as an integer, such as to determine unit optimal combination or running numbers. Linear programming is only suitable for linear objective function and constraint, therefore, its application scope is limited. Nonlinear pro- 
gramming method requires continuous and differentiable objective function and constraint conditions, so it is not applicable to pumping station optimal operation in some cases.

\section{Dynamic programming}

Dynamic programming is a multi-stage decision optimization method.

Cheng J L, et al. (2010) researched daily operation optimization problems for single pumping station by dynamic programming. Gong Y, et al. (2014) studied the water level optimization of water transferring channel in multi-stage pumping stations based on head-water level success by dynamic programming. Shi Z T, et al. (2015) solved the nonlinear mathematical model of water resource optimal operation for a single reservoir and single water supply pumping station, by dynamic programming successive approximation method.

Dynamic programming method plays an important role in solving pumping station optimization. Optimization model are more and more complex with more factors, and the calculation amount will be significantly increased when the discrete points of state variables are increased.

\section{Intelligent algorithms}

With the development of computer technology, new algorithms have been widely applied, which promote the optimal operation of the pump stations.

Taking minimum pump operation cost as the goal, Bagirov A M, et al. (2013) determined pump operation scheduling scheme in a water conveyance system by Hooke-Jeeves direct search algorithm.

Zhang J Z, et al. (2012) and Behandish M et al. (2014) established optimization model using neural network, and solved it by particle swarm optimization algorithm and genetic algorithm respectively.

Yan B P \& Cheng L (2010) researched variable speed optimization of the water supply pump station by chaos algorithm of problem, and got a good calculation accuracy and high reliability.

Feng X L, et al. (2011) solved a single pumping station system optimal operation problem by the genetic algorithm, basic particle swarm algorithm and simulated annealing particle swarm algorithm, and the results showed that the simulated annealing particle swarm algorithm is faster with higher precision.

Liang X, et al. (2013) established the optimization model of cascade pumping stations aiming at minimum electricity cost on the basis of flow balance, considering different electricity price at different time, and solved the model by the immune particle swarm algorithm.

Tang Y L, et al. (2014) studied pumping unit boot combination switch and the run time optimization problem with particle swarm optimization algorithm.

The above various optimization methods have their advantages, disadvantages and applicability, so it is necessary to choose appropriate methods according to the established models.

\section{DEVELOPING TREND}

There are more results about the optimal operation of single stage or parallel pumping station group, and less about large multi-stage pumping station system, also complete theoretical system has not been formed.

(1) Research scopes of pump station optimal operation. For large pump station operation optimization, the research scope is expanded gradually. It develops from the economic operation of water pump and pump assembly to that of a single pump station, parallel pumping station group and multi-stage pumping stations. Factors are more and more comprehensive. Also, the optimizing goal is gradually developed from the highest pump efficiency to the highest pump assembly efficiency and pumping station efficiency. In addition to the main unit energy consumption in the pumping stations, there are auxiliary equipment, power transmission and transformation facilities and energy consumption of water conveyance system, etc. The optimizing operation is not in the point of whole system, and the optimization effect could be improved. The preliminary study found that the highest efficiency point of a pumping station system is deviated from that of a pump unit.

(2) Methods to optimizing operation model of the pumping station. For simple models of pump stations optimal operation, better optimization effect could be gained by some new algorithm. But, for complex mathematical models, the problems such as low speed, low precision and poor convergence are existed even by new algorithms. Therefore, according to the characteristics of large pump station system optimal operation model, we should research better methods from the computation 
speed, precision and convergence to seek suitable optimization algorithm for solving pump stations optimal operation.

(3) Instruction theory of the pump station operation. In our country, pump blade or rotational speed adjusting mechanism is installed in many large pumping stations. But the pump unit usually operates at design speed or blade angles in practice, due to lacking of practical theoretical guidance of operation, and the station fails to realize the economic operation. Therefore, for pumping station system, we should study the complete optimizing operation theory to determine the operation schemes to guide pumping station operation.

\section{ACKNOWLEDGMENTS}

The work was supported by Natural Science Foundation of Jiangsu Province, China (Grant No. BK20130448), and Natural Science Foundation of the Jiangsu Higher Education Institutions of China (Grant No. 13KJB570004).

\section{REFERENCES}

[1] Anagnostopoulos J S, Papantonis D E. 2007. Pumping station design for a pumped-storage wind-hydro power plant. Energy Conversion and Management, Vol. 48: 3009-3017

[2] Bagirov A M, Barton A F, Mala-Jetmarova H, et al. 2013. An Algorithm for Minimization of Pumping Costs in Water Distribution Systems using a Novel Approach to Pump Scheduling. Mathematical and Computer Modelling, 57(3-4): 873-886

[3] Behandish M, Wu Z Y. 2014. Concurrent pump scheduling and storage level optimization using meta-models and evolutionary algorithms. Procedia Engineering, Vol.70: 103-112

[4] Chen S L, Rui J, Xu Q, et al. 2003. Optimal operation of the pumping station daily scheduling. Water Resources and Power, 21(3): 82-83

[5] Cheng J L, Zhang L H, Zhang R T, et al. 2010. Study on optimal daily operation of single adjustable-blade pump unit in pumping station. Journal of Hydraulic Engineering, 41(4): 499-504

[6] Coelho B, Andrade-Campos A. 2014. Efficiency achievement in water supply systems-a review. Renewable and Sustainable Energy Reviews, Vol. 30: 59-84

[7] Feng X L, Qiu B Y, Cao H H et al. 2009. Optimal operation for Baoying Pumping Station in East Route Project of South-to-North Water Transfer. Chinese Journal of Mechanical Engineering, 22(1): 78-83

[8] Feng X L, Qiu B Y, Huang H T, et al. 2008. Study on optimal operation of Jiangdu pump stations in Eastern Route of South-to-North Water Diversion Project. Journal of Hydroelectric Engineering, 27(4): 130-134

[9] Feng X L, Qiu B Y, Yang X L, et al. 2011. Optimal methods and its application of large pumping station operation. Journal of Drainage and Irrigation Machinery Engineering, 29(2): 127132

[10] Ghaddar B, Naoum-Sawaya J, Kishimoto A, et al. 2015. A Lagrangian decomposition approach for the pump scheduling problem in water networks. European Journal of Operational Research, 241(2): 490-501

[11] Gong Y, Cheng J L, Liu J S. 2014. Water level optimization of water transferring channel in multi-stage pumping stations based on head-water level successive approximation optimization method. Transactions of the Chinese Society of Agricultural Engineering, 30(22): 120-129

[12] Liang X, Liu M Q, Liu Z Y, et al. 2013. Optimum dispatching of multistage pumping station based on mixed particle swarm optimization. Engineering Journal of Wuhan University, 46(4): 536-539

[13] Moreno M A, Carrión P A, Planells P, et al. 2007. Measurement and improvement of the energy efficiency at pumping stations. Biosystems Engineering, Vol. 98: 479-486

[14] Ommen T, Markussen W B, Elmegaard B. 2014. Comparison of linear, mixed integer and nonlinear programming methods in energy system dispatch modelling. Energy, Vol. 74: 109-118

[15] Puleo V, Morley M, Freni G, Savi D. 2014. Multi-stage linear programming optimization for 
pump scheduling. Procedia Engineering, Vol. 70:1378-1385

[16] Qiu B Y, Feng X L, Huang J Y, et al. 2005. Study on economical operation of large pump station by adjusting operation duty. 8th Asian International Fluid Machinery Conference, China, 12-15 October 2005:856-870

[17] Shi Z T, Cheng J L, Yang S T, et al. 2015. Research on methods of optimal water resources allocation for "single reservoir-single pump station" system using DPSA. Journal of Irrigation and Drainage, Issue 2: 37-40

[18] Skworcow P, Paluszczyszyn D, Ulanicki B, et al. 2014. Optimisation of pump and valve schedules in complex large-scale water distribution systems using GAMS modelling language. Procedia Engineering, Vol.70: 1566-1574

[19] Tang Y, Zhao K, Yang J, et al. 2010. Parallel pumps based on the one variable-speed optimal operation. China Rural Water and Hydropower, Issue 10:139-141, 144

[20] Tang Y L, Zheng G L, Zhang S R. 2014. Optimal control approaches of pumping stations to achieve energy efficiency and load shifting. International Journal of Electrical Power \& Energy Systems, Vol. 55: 572-580

[21] Theocharisa M E, Tzimopoulosb C D, Sakellariou- Makrantonakic M A, et al. 2010. Comparative calculation of irrigation networks using Labye's method, the linear programming method and a simplified nonlinear method. Mathematical and Computer Modelling, 51(3-4):286-299

[22] Vilanova M R N, Balestieri J A P. 2014. Energy and hydraulic efficiency in conventional water supply systems. Renewable and Sustainable Energy Reviews, Vol.30: 701-714

[23] Wu H, Zhou Z H, Gao Y, et al. 2014. Research of optimized dispatching of cascade pumping stations based on hydrodynamic dispersion model and genetic algorithm. Haihe Water Resources, Issue 4: 46-49

[24] Yan B P, Cheng L. 2010. Optimal operation of water-supply pumping station by chaos. Journal of Irrigation and Drainage, 28(1): 56-58

[25] Zhang Z J, Zeng Y H, Kusiak A. 2012. Minimizing Pump Energy in a Wastewater Processing Plant. Energy, 47(1): 505-514 